\title{
EXAMINATION OF HILL'S LATEST YIELD CRITERION USING EXPERIMENTAL DATA FOR VARIOUS ANISOTROPIC SHEET METALS
}

\author{
S. KoBayashI \\ Department of Mechanical Engineering, University of California at Berkeley, U.S.A.
}

R. M. Caddell* and W. F. Hosford $†$

- Department of Mechanical Engineering and Applied Mechanies and †Department of Materials and Metallurgical Engineering, The University of Michigan, Ann Arbor, Michigan, U.S.A.

(Received 15 November 1984; and in revised form 13 April 1985)

\begin{abstract}
Summary-Using experimental data publishod earlier [Vial et al., Int. J. Mech. Sci. 25, 899 (1983)], values of the exponent $m$ in the Hill (1979) yield criterion [Hill, Math. Proc. Cambridge Phil. Sac. 85, 179 (1979)] are calculated for each of the four special cases suggested. With these findings, stress-strain relations for plane-strain compression are derived and predictions using these derived equations are compared with experimental results. Compurisons between prediction and experiment are reasonable in all cases and it is suggested that the discrepancies could arise bocause of the assumption of planar isotropy (via the use of an average $r$-value) and because the exponent $m$ apparently varies with induced strain.
\end{abstract}

\section{NOTATION}

$\sigma_{1}, \sigma_{2}, \sigma_{3}$ principal stresses, where $\sigma_{1} \geqslant \sigma_{2} \geqslant \sigma_{3}$

$f, g, h, a, b, c$ anisotropic parameters in Hill (1979) yield criterion

$r$ average strain ratio

$\sigma_{\mathrm{u}}=\sigma_{1}$ yield stress in uniaxial tension, $\sigma_{2}=\sigma_{3}=0$

$\sigma_{b}=\sigma_{1}=\sigma_{2}$ yield stress in balanced biaxial tension, $\sigma_{3}=0$

$\sigma_{p}=\sigma_{3}$ yield stress in plane-strain compression, $\sigma_{1}=0$, and $0>\sigma_{2}>\sigma_{3}$

$x=\frac{\sigma_{2}}{\sigma_{0}}$ stress ratio in plane-strain compression, for $\dot{\varepsilon}_{2}=0$ and $\sigma_{1}=0$

$m$ exponent in Hill (1979) yield criterion

$\dot{\varepsilon}_{1}, \dot{\varepsilon}_{2}, \dot{\varepsilon}_{3}$ principal strain-rates

$\varepsilon_{w}$ true strain in uniaxial tension

$\varepsilon_{p}$ true thickness strain in plane-strain compression

$K_{u}$ strength coefficient in uniaxial tension

$n_{u}$ strain-hardening exponent in uniaxial tension

$K_{p}$ strength coefficient in plane-strain compression

$n_{b}$ strain-hardening exponent in balanced biaxial tension

$K_{b}$ strain-hardening exponent in balanced biaxial tension

\section{INTRODUCTION}

IN 1979, Hill [2] proposed the following anisotropic yield criterion:

$$
\begin{aligned}
f \mid \sigma_{2}- & \left.\sigma_{3}\right|^{m}+g\left|\sigma_{3}-\sigma_{1}\right|^{m}+h\left|\sigma_{1}-\sigma_{2}\right|^{m}+a\left|2 \sigma_{1}-\sigma_{2}-\sigma_{3}\right|^{m} \\
& +b\left|2 \sigma_{2}-\sigma_{3}-\sigma_{1}\right|^{m}+c\left|2 \sigma_{3}-\sigma_{1}-\sigma_{2}\right|^{m}=\sigma^{m},
\end{aligned}
$$

where loading is coaxial with the orthotropy, the coefficients $f g$, etc., characterize the anisotropy, $\sigma$ is a scaling factor that regulates the unit of stress, and $m>1$ to insure convexity.

Following Hill's procedure, and for the most general situation, increments of stress tangential to the yield surface are given by

$$
\begin{aligned}
f \mid \sigma_{2} & -\left.\sigma_{3}\right|^{m-1} \mathrm{~d}\left(\sigma_{2}-\sigma_{3}\right)-g\left|\sigma_{3}-\sigma_{1}\right|^{m-1} \mathrm{~d}\left(\sigma_{3}-\sigma_{1}\right)+h\left|\sigma_{1}-\sigma_{2}\right|^{m-1} \mathrm{~d}\left(\sigma_{1}-\sigma_{2}\right) \\
& +a\left|2 \sigma_{1}-\sigma_{2}-\sigma_{3}\right|^{m-1} \mathrm{~d}\left(2 \sigma_{1}-\sigma_{2}-\sigma_{3}\right) \pm b\left|2 \sigma_{2}-\sigma_{3}-\sigma_{1}\right|^{m-1} \mathrm{~d}\left(2 \sigma_{2}-\sigma_{3}-\sigma_{1}\right) \\
& -c\left|2 \sigma_{3}-\sigma_{1}-\sigma_{2}\right|^{m-1} \mathrm{~d}\left(2 \sigma_{3}-\sigma_{1}-\sigma_{2}\right)=0 .
\end{aligned}
$$

Note that in equation (2) the ordering of stresses is $\sigma_{1} \geqslant \sigma_{2} \geqslant \sigma_{3}$ and the \pm signs are determined according to $2 \sigma_{2}-\sigma_{3}-\sigma_{1} \gtrless 0$. 
By the normality flow rule, the principal components of strain-rate satisfy

$$
\sigma_{1} \dot{\varepsilon}_{1}+\sigma_{2} \dot{\varepsilon}_{2}+\sigma_{3} \dot{\varepsilon}_{3}>0 \text { and } \dot{\varepsilon}_{1} \mathrm{~d} \sigma_{1}+\dot{\varepsilon}_{2} \mathrm{~d} \sigma_{2}+\dot{\varepsilon}_{3} \mathrm{~d} \sigma_{3}=0
$$

for all increments in equation (2). By direct comparison of the differential forms,

$$
\dot{\varepsilon}_{1}+\dot{\varepsilon}_{2}+\dot{\varepsilon}_{3}=0
$$

(which implies constancy of volume) with

$$
\begin{aligned}
& \left\{f\left|\sigma_{2}-\sigma_{3}\right|^{m-1}-h\left|\sigma_{1}-\sigma_{2}\right|^{m-1}-a\left|2 \sigma_{1}-\sigma_{2}-\sigma_{3}\right|^{m-1} \pm 2 b\left|2 \sigma_{2}-\sigma_{3}-\sigma_{1}\right|^{m-1}\right. \\
\frac{\dot{\varepsilon}_{2}}{\dot{\varepsilon}_{3}}= & \frac{\left.+c\left|2 \sigma_{3}-\sigma_{1}-\sigma_{2}\right|^{m-1}\right\}}{\left\{-f\left|\sigma_{2}-\sigma_{3}\right|^{m-1}-g\left|\sigma_{3}-\sigma_{1}\right|^{m-1}-a\left|2 \sigma_{1}-\sigma_{2}-\sigma_{3}\right|^{m-1} \mp b\left|2 \sigma_{2}-\sigma_{3}-\sigma_{1}\right|^{m-1}\right.} \\
& \left.-2 c\left|2 \sigma_{3}-\sigma_{1}-\sigma_{2}\right|^{m-1}\right\} .
\end{aligned}
$$

For uniaxial tension $\left(\sigma_{w}, 0,0\right)$, equation (1) gives

$$
\left(g+h+a 2^{m}+b+c\right) \sigma_{u}^{m}=\sigma^{m}
$$

and equation (5) reduces to

$$
r=\frac{\dot{\varepsilon}_{2}}{\dot{\varepsilon}_{3}}=\frac{a 2^{m-1}+h+2 b-c}{a 2^{m-1}+g-b+2 c} .
$$

Under balanced biaxial tension $\left(\sigma_{b}, \sigma_{b}, 0\right)$, equation (1) gives

$$
\left(f+g+a+b+c 2^{m}\right) \sigma_{b}^{m}=\sigma^{m} .
$$

Combining equations (6) and (8) gives

$$
\left(\frac{\sigma_{b}}{\sigma_{u}}\right)^{m}=\frac{g+h+a 2^{m}+b+c}{f+g+a+b+c 2^{m}}
$$

With plane-strain compression (say, $\left.\dot{\varepsilon}_{2}=0\right)$ it is reasonble to assume that the stress state $\left(\sigma_{1}\right.$, $\left.\sigma_{2}, \sigma_{3}\right)$ can be taken as $\left(0>\sigma_{2}>\sigma_{p}=\sigma_{3}\right)$. Using equation (5) with $\dot{\varepsilon}_{2}=0$ gives

$$
f|x-1|^{m-1}-h|x|^{m-1}-a|x+1|^{m-1} \pm 2 b|2 x-1|^{m-1}+c|2-x|^{m-1}=0,
$$

where $x=\sigma_{2} / \sigma_{3}=\sigma_{2} / \sigma_{p}$ and the \pm sign corresponds to $0<x<\frac{1}{2}$ and $\frac{1}{2}<x<1$. Using equations (1) and (5), and noting that $\sigma_{p}$ is always negative, we find

$$
\left(-\frac{\sigma_{p}}{\sigma_{u}}\right)^{m}=\frac{\left(g+h+a 2^{m}+b+c\right)}{f|x-1|^{m}+g+h|x|^{m}+a|x+1|^{m}+b|2 x-1|^{m}+c|2-x|^{m}} .
$$

\section{RELATIONS FOR IN-PLANE ISOTROPY}

With planar isotropy, we note that $f=g$ and $a=b$, then equations (7), (9), (10), and (11) reduce to

$$
\begin{gathered}
r=\frac{\left(2^{m-1}+2\right) a-c+h}{\left(2^{m-1}-1\right) a+2 c+f} \\
\left(\begin{array}{c}
\sigma_{b} \\
\sigma_{\mathrm{u}}
\end{array}\right)^{m}=\frac{\left(2^{m}+1\right) a+c+f+h}{2 a+c 2^{m}+2 f} \\
f|x-1|^{m-1}-h|x|^{m-1}-\mathrm{a}|x+1|^{m-1} \pm 2 a|2 x-1|^{m-1}+c|2-x|^{m-1}=0 \\
\left(-\frac{\sigma_{\mathrm{p}}}{\sigma_{\mathrm{u}}}\right)^{m}=\frac{\left(2^{m}+1\right) a+c+f+h}{f\left\{|x-1|^{m}+1\right\}+h|x|^{m}+a\left\{|x+1|^{m}+|2 x-1|^{m}\right\}+c|2-x|^{m}} .
\end{gathered}
$$

\section{SPECIAL CASES APPLIED TO HILL'S CRITERION (equation 1)}

Hill suggested four simple versions of equation (1) which with planar isotropy and particular values of the coefficients, alter equations ( 12 to 15 ) as follows:

Case 1

Where $a=b=0, h=0, f=g$

$$
\frac{f}{c}=-\left(\frac{1}{r}+2\right)
$$




$$
\begin{aligned}
\left(\frac{\sigma_{b}}{\sigma_{u}}\right)^{m} & =\frac{1+\frac{f}{c}}{2^{m}+2 \frac{f}{c}} \\
\left(-\frac{\sigma_{p}}{\sigma_{u}}\right)^{m}= & \frac{1+\frac{f}{c}}{\frac{f}{c}\left\{|x-1|^{m}+1\right\}+|2-x|^{m}} \\
-\frac{f}{c} & =\left|\frac{2-x}{x-1}\right|^{m-1} .
\end{aligned}
$$

where

Case 2

$$
\begin{aligned}
& \text { Where } a=b, c=0, f=g=0 \\
& \qquad \frac{h}{a}=2^{m-1}(r-1)-r-2 \\
& \left(\frac{\sigma_{b}}{\sigma_{u}}\right)^{m}=\frac{2^{m}+1+\frac{h}{a}}{2} \\
& \left(-\frac{\sigma_{p}}{\sigma_{u}}\right)^{m}=\frac{2^{m}+1+\frac{h}{a}}{\frac{h}{a}|x|^{m}+|x+1|^{m}+|2 x-1|^{m}},
\end{aligned}
$$

where

$$
-\frac{h}{a}|x|^{m-1}-|x+1|^{m-1} \pm 2|2 x-1|^{m-1}=0
$$

according to $x>\frac{1}{2}$.

Case 3

$$
\text { Where } a=b, c=0, f=g, h=0
$$

$$
\begin{gathered}
\frac{f}{a}=\frac{2^{m-1}+2}{r}-\left(2^{m-1}-1\right) \\
\left(\frac{\sigma_{b}}{\sigma_{u}}\right)^{m}=\frac{2^{m}+1+\frac{f}{a}}{2+2 \frac{f}{a}} \\
\left(-\frac{\sigma_{p}}{\sigma_{u}}\right)^{m}=\frac{2^{m}+1+\frac{f}{a}}{\frac{f}{a}\left\{|x-1|^{m}+1\right\}+|x+1|^{m}+|2 x-1|^{m}},
\end{gathered}
$$

where

$$
\frac{f}{a}|x-1|^{m-1}-|x+1|^{m-1} \pm 2|2 x-1|^{m-1}=0
$$

according to $x \lessgtr \frac{1}{2}$.

\section{Case 4}

Where $a=b=0, f=g=0$

$$
\begin{gathered}
\frac{h}{c}=2 r+1 \\
\left(\frac{\sigma_{b}}{\sigma_{u}}\right)^{m}=\frac{1+\frac{h}{c}}{2^{m}} \\
\left(-\frac{\sigma_{p}}{\sigma_{u}}\right)^{m}=\frac{1+\frac{h}{c}}{\frac{h}{c}|x|^{m}+|2-x|^{m}}
\end{gathered}
$$


where

or

$$
-\frac{h}{c}|x|^{m-1}+|2-x|^{m-1}=0
$$

$$
\frac{h}{c}=\left|\frac{2-x}{x}\right|^{m-1} \text {. }
$$

Dodd and Caddeil [3] used Hill's criterion [2]; discuss anomalous behavior; previously published data [4-6] were included. Although equations (17), (21), (25) and (29) are equivalent to equations for $\left(\sigma_{b} / \sigma_{u}\right)^{m}$ used in [3], the forms used here are expressed in terms of the coefficients $a, b, c$, etc. and the stress ratio, $x$, instead of the strain ratio, $r$, as used in [3]. This provides consistency with the expressions for $\left(-\sigma_{p} / \sigma_{y}\right)^{m}$ used in this paper; those expressions were not considered in [3]. To assist the reader, the formulation of $\left(\sigma_{b} / \sigma_{v}\right)^{m}$ are included here for completeness.

\section{COMPARISON OF PREDICTIONS WITH EXPERIMENTS}

For all cases in the previous section, it can be seen that the values of $r$ and $m$ define the yield criterion. Now $r$ is found experimentally and $m$ can be determined from two tests, say, uniaxial and balanced biaxial tension, with the use of equations (17), (21), (25), and (29). Vial et al. [1] performed experiments using uniaxial tension, uniaxial (through thickness) compression, balanced biaxial tension, and plane-strain compression using four sheet metals. The relevant experimental results are shown in Tables 1 to 3 for the reader's convenience. Using the average values of $r, K_{w}$, and $n_{u}$ from the uniaxial tensile tests and the values of $K_{b}$ and $n_{b}$ from the balanced biaxial tension tests, $m$ values were determined at various strains for all four metals. To do this, the equivalence between the two tests must be considered. Instead of attempting to derive such equivalence in a general form, we have applied directly the

TABLE 1, UNIAXIAL TENSION TESTS

\begin{tabular}{lccccc}
\hline Material & $\begin{array}{c}\text { Angle } \\
\left({ }^{\circ}\right.\end{array}$ & $\begin{array}{c}\boldsymbol{K} \\
(\mathrm{MPa})\end{array}$ & $n$ & $\begin{array}{c}\text { Range of } \\
\text { strain }\end{array}$ & $\begin{array}{c}\text { Strain ratio } \\
(\boldsymbol{R})\end{array}$ \\
\hline $\begin{array}{l}\text { Al-killed } \\
\text { steel }\end{array}$ & 0 & 520.2 & 0.237 & $0.02-0.24$ & \\
& 90 & 511.8 & 0.235 & $0.02-0.24$ & 1.950 \\
& 45 & 533.0 & 0.233 & $0.02-0.24$ & 2.318 \\
& av & 524.9 & 0.234 & $0.02-0.24$ & 1.470 \\
Aluminum & 0 & 195.5 & 0.214 & $0.02-0.24$ & 1.802 \\
& 90 & 183.2 & 0.215 & $0.02-0.24$ & 0.655 \\
& 45 & 187.1 & 0.222 & $0.02-0.24$ & 0.510 \\
Copper & av & 188.1 & 0.218 & $0.02-0.24$ & 0.753 \\
& 0 & 465.7 & 0.362 & $0.02-0.28$ & 0.870 \\
& 90 & 433.9 & 0.364 & $0.02-0.31$ & 0.818 \\
& 45 & 436.8 & 0.361 & $0.02-0.36$ & 0.449 \\
Brass 260 & av & 443.3 & 0.362 & $0.02-0.28$ & 0.654 \\
& 0 & 828.8 & 0.493 & $0.08-0.39$ & 0.944 \\
& 90 & 828.6 & 0.498 & $0.08-0.39$ & 0.743 \\
& 45 & 809.7 & 0.495 & $0.08-0.39$ & 0.841 \\
& av & 819.2 & 0.495 & $0.08-0.39$ & 0.842 \\
\hline
\end{tabular}

\begin{tabular}{|c|c|c|c|}
\hline Material & $\begin{array}{c}K \\
(\mathbf{M P a})\end{array}$ & $n$ & Range of strain \\
\hline \multicolumn{4}{|c|}{ Biaxial tension stress vs thickness strain curves } \\
\hline $\begin{array}{l}\text { Al-killed steel } \\
\text { Aluminum } 3003-0 \\
\text { Copper } 110 \\
\text { Brass } 260\end{array}$ & $\begin{array}{l}712.6 \\
171.3 \\
444.6 \\
848.0\end{array}$ & $\begin{array}{l}0.278 \\
0.170 \\
0.368 \\
0.465\end{array}$ & $\begin{array}{l}0.06-0.25 \\
0.055-0.33 \\
0.09-0.42 \\
0.10-0.25\end{array}$ \\
\hline \multicolumn{4}{|c|}{ Uniaxial compression stress vs thickness strain curves } \\
\hline $\begin{array}{l}\text { Al-killed steel } \\
\text { Aluminum } 3003-0 \\
\text { Copper } 110 \\
\text { Brass } 260\end{array}$ & $\begin{array}{l}661.2 \\
176.9 \\
418.8 \\
787.8\end{array}$ & $\begin{array}{l}0.248 \\
0.2034 \\
0.334 \\
0.442\end{array}$ & $\begin{array}{l}0.013-0.27 \\
0.027-0.35 \\
0.025-0.32 \\
0.065-0.24\end{array}$ \\
\hline
\end{tabular}

TABle 2. Biaxial tension AND UNIAXIAL COMPRESSION TESTS 
Table 3. Plane-strain compression tests

\begin{tabular}{|c|c|c|c|c|}
\hline Material & $\begin{array}{c}K \\
(\mathbf{M P a})\end{array}$ & $n$ & Range of strain & Lubricant \\
\hline \multicolumn{5}{|c|}{ (a) Plane-strain compression $\left(\varepsilon_{y}=0\right)$} \\
\hline $\begin{array}{l}\text { Al-killed steel } \\
\text { Aluminum 3003-0 } \\
\text { Copper } 110 \\
\text { Brass } 260\end{array}$ & $\begin{array}{r}805.0 \\
812.0 \\
212.7 \\
505.9 \\
448.9 \\
1012.9 \\
950.5\end{array}$ & $\begin{array}{l}0.256 \\
0.268 \\
0.204 \\
0.369 \\
0.304 \\
0.469 \\
0.457\end{array}$ & $\begin{array}{l}0.055-0.36 \\
0.055-0.35 \\
0.03-0.35 \\
0.04-0.36 \\
0.10-0.37 \\
0.07-0.29 \\
0.06-0.31\end{array}$ & $\begin{array}{l}\mathrm{MoS}_{2} \\
\text { Teflon } \\
\mathrm{MoS}_{2} \\
\mathrm{MoS}_{2} \\
\text { Teflon } \\
\mathrm{MoS}_{2} \\
\text { Teflon }\end{array}$ \\
\hline \multicolumn{5}{|c|}{ (b) Plane-strain compression $\left(\varepsilon_{x}=0\right)$} \\
\hline $\begin{array}{l}\text { Al-killed steel } \\
\text { *Aluminum } 3003-0 \\
\text { Copper } \\
\text { Brass } 260\end{array}$ & $\begin{array}{l}826.9 \\
836.1 \\
197.4 \\
483.8 \\
497.2 \\
927.4 \\
951.7\end{array}$ & $\begin{array}{l}0.259 \\
0.266 \\
0.214 \\
0.362 \\
0.386 \\
0.453 \\
0.471\end{array}$ & $\begin{array}{l}0.05-0.31 \\
0.05-0.27 \\
0.02-0.5 \\
0.075-0.41 \\
0.08-0.33 \\
0.07-0.34 \\
0.09-0.34\end{array}$ & $\begin{array}{l}\mathrm{MoS}_{2} \\
\text { Teflon } \\
\mathrm{MoS}_{2} \\
\mathrm{MoS}_{2} \\
\text { Teflon } \\
\text { MoS }_{2} \\
\text { Teflon }\end{array}$ \\
\hline
\end{tabular}

* When Teflon was used with aluminum, results were questionable

TABLE 4. VARIATIONS OF m-VALUES AT DIFFERENT STRAINS

\begin{tabular}{|c|c|c|c|c|}
\hline \multicolumn{5}{|c|}{ m-values (Al-killed steel) } \\
\hline$\varepsilon_{u}$ & Case I & Case II & Case III & Case IV \\
\hline 0.060 & 1.984 & 1.970 & 1.919 & 2.044 \\
\hline 0.100 & 1.999 & 1.998 & 1.995 & 2.022 \\
\hline 0.140 & 2.009 & 2.017 & 2.044 & 1.977 \\
\hline 0.180 & 2.016 & 2.032 & 2.084 & 1.956 \\
\hline 0.220 & 2.022 & 2.046 & 2.115 & 1.941 \\
\hline \multicolumn{5}{|c|}{ m-values (aluminum) } \\
\hline 0.060 & 2.219 & 2.189 & 3.080 & 1.667 \\
\hline 0.100 & 2.184 & 2.152 & 2.826 & 1.717 \\
\hline 0.140 & 2.166 & 2.128 & 2.680 & 1.751 \\
\hline 0.180 & 2.142 & 2.111 & 2.578 & 1.778 \\
\hline 0.220 & 2.127 & 2.098 & 2.502 & 1.780 \\
\hline \multicolumn{5}{|c|}{ m-values (copper) } \\
\hline 0.040 & 2.160 & 2.125 & 2.667 & 1.754 \\
\hline 0.100 & 2.167 & 2.132 & 2.710 & 1.743 \\
\hline 0.180 & 2.172 & 2.137 & 2.738 & 1.736 \\
\hline 0.280 & 2.175 & 2.141 & 2.758 & 1.731 \\
\hline 0.340 & 2.177 & 2.202 & 2.766 & 1.729 \\
\hline \multicolumn{5}{|c|}{$m$-values (brass) } \\
\hline 0.040 & 2.185 & 2.202 & 2.997 & 1.682 \\
\hline 0.100 & 2.161 & 2.169 & 2.814 & 1.722 \\
\hline 0.180 & 2.143 & 2.147 & 2.699 & 1.749 \\
\hline 0.280 & 2.131 & 2.131 & 2.617 & 1.771 \\
\hline 0.340 & 2.125 & 2.124 & 2.583 & 1.780 \\
\hline
\end{tabular}

equivalence of mechanical work for these two tests as follows, noting that power-law hardening is displayed by both. The work per unit volume is the area beneath the stress-strain curve up to the strain considered. So, if $\sigma_{k}=K_{u} \varepsilon_{u}^{n_{k}}$ in uniaxial tension. then the work per unit volume is

$$
w_{u}=\frac{K_{u} \varepsilon_{u}^{n_{u}+1}}{n_{u}+1}
$$


Table 5. Predictions of Plane-strain COMPression for EACH CASE

\begin{tabular}{|c|c|c|c|c|}
\hline \multirow[b]{2}{*}{ Case } & \multicolumn{3}{|c|}{ Al-killed steel $\left(R_{a v}=1.802\right)$} & \multirow[b]{2}{*}{$K_{p}$} \\
\hline & $m^{*}$ & $x$ & $-\sigma_{p} / \sigma_{u}$ & \\
\hline I & 1.999 & 0.357 & 1.305 & 728.9 \\
\hline II & 1.998 & 0.358 & 1.305 & 729.1 \\
\hline III & 1.995 & 0.358 & 1.305 & 729.1 \\
\hline IV & 2.022 & 0.358 & 1.305 & 729.2 \\
\hline \multicolumn{5}{|c|}{ Aluminum $\left(\boldsymbol{R}_{a v}=0.668\right)$} \\
\hline I & 2.184 & 0.467 & 1.150 & 223.0 \\
\hline II & 2.152 & 0.418 & 1.113 & 214.3 \\
\hline III & 2.826 & 0.449 & 1.135 & 219.5 \\
\hline IV & 1.717 & 0.469 & 1.128 & 217.7 \\
\hline \multicolumn{5}{|c|}{ Copper $\left(R_{a v}=0.654\right)$} \\
\hline I & 2.167 & 0.486 & 1.139 & 529.4 \\
\hline II & 2.132 & 0.455 & 1.105 & 507.7 \\
\hline III & 2.710 & 0.474 & 1.126 & 521.1 \\
\hline IV & 1.743 & 0.490 & 1.120 & 517.1 \\
\hline \multicolumn{5}{|c|}{ Brass $\left(\boldsymbol{R}_{a v}=0.842\right)$} \\
\hline I & 2.161 & 0.416 & 1.197 & 1072.1 \\
\hline II & 2.169 & 0.353 & 1.161 & 1024.4 \\
\hline III & 2.814 & 0.385 & 1.180 & 1048.8 \\
\hline IV & 1.722 & 0.406 & 1.173 & 1039.4 \\
\hline
\end{tabular}

* $m$-value calculated from $\varepsilon_{\mathrm{u}}=0.1$.

and, if $\sigma_{b}=K_{b} \varepsilon_{b}^{n_{b}}$ in balanced biaxial tension ( $\varepsilon_{b}$ : magnitude equal to the thickness strains in biaxial tension) is

$$
w_{b}=\frac{K_{b} \varepsilon_{b}^{n_{b}+1}}{n_{b}+1} .
$$

Considering $w_{u}=w_{b}, \varepsilon_{b}$ can be explicitly expressed as

$$
\varepsilon_{b}=\left[\frac{K_{u}\left(n_{b}+1\right)}{K_{b}\left(n_{u}+1\right)} \varepsilon_{u}^{n_{u}+1}\right]^{1 /\left(n_{b}+1\right)} .
$$

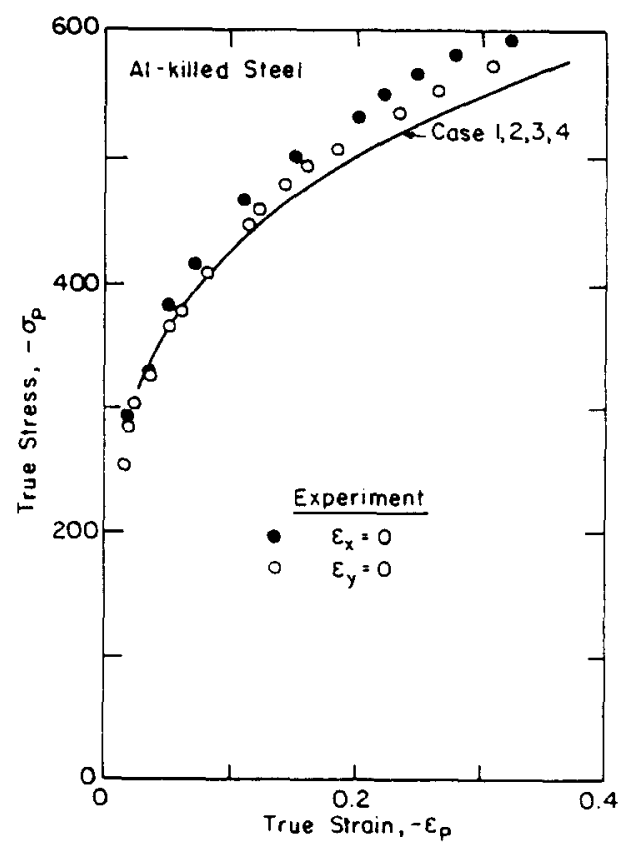

FIG. 1. Plane-strain compression results comparing predictions vs experiment for an Al-killed steel. 


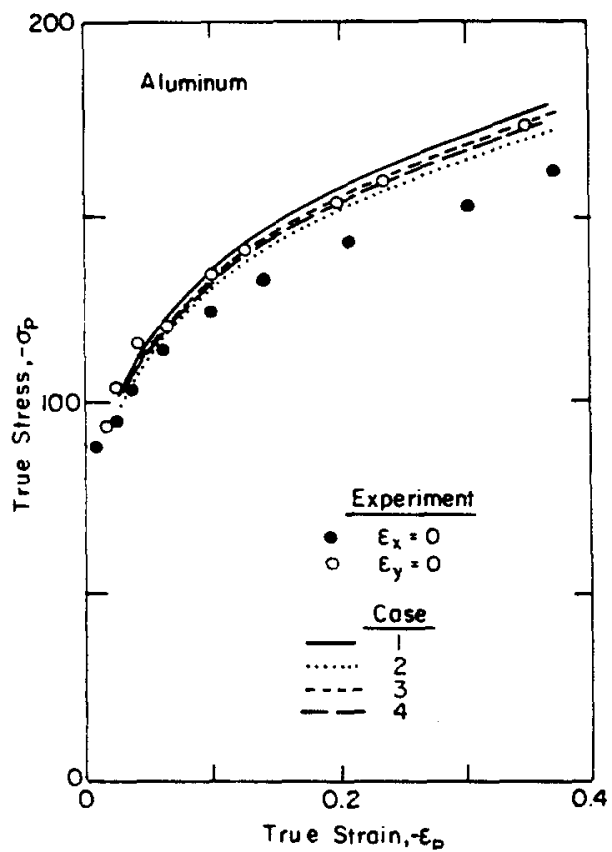

FIG. 2. Plane-strain compression results comparison predictions vs experiment for an aluminum alloy (3003-0).

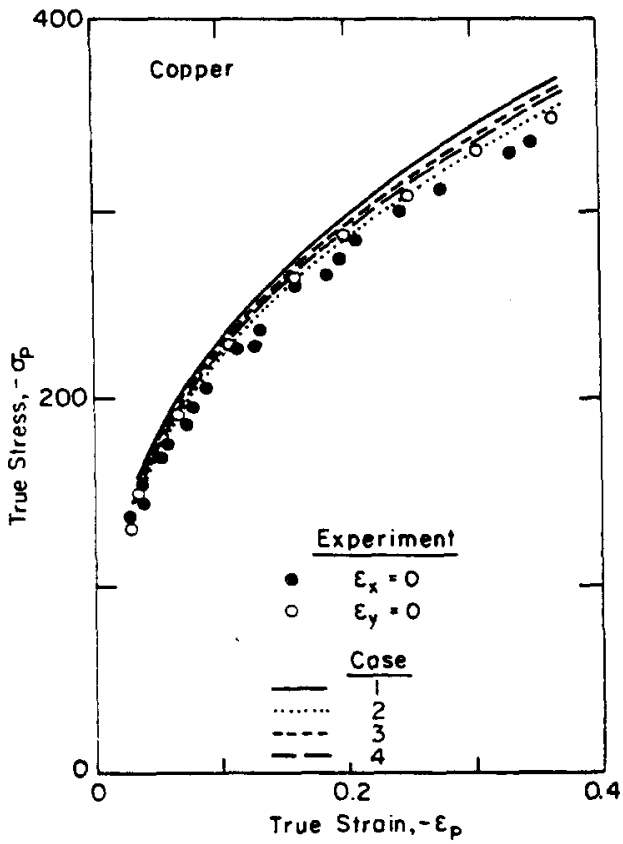

FIG. 3. Plane-strain compression results comparing predictions vs experiment for $\mathrm{Cu}-110$.

A sample calculation indicates how the $\boldsymbol{m}$-values in Table 4 were determined. Consider the Al-killed steel, where, from Table 1, the average values of interest are $r=1.802, K_{u}=524.9$, and $n_{u}=0.234$; from Table $2, K_{b}=712.6$ and $n_{b}=0.278$. For a uniaxial strain of $\varepsilon_{u}=0.100$, the balaced biaxial strain that gives the same amount of plastic of work is 0.0876 from equation (34). The stress, $\sigma_{u}$, for $\varepsilon_{u}=0.100$, is $\sigma_{u}=524.9(0.1)^{0.234}=306.25$, while the stress $\sigma_{b}$, for $\varepsilon_{b}$ $=0.0876$ is $\sigma_{b}=712.6(0.0876)^{0.278}=362.13$. Thus, $\sigma_{b} / \sigma_{k}=1.1825$.

For Case 1, from equation (16), $f / c=-2.5549$ and with the ratio of $\sigma_{b} / \sigma_{u}$ of $1.1825, \mathrm{~m}$ is found, using equation (17). to be 1.999. Each of the four cases has been used for a range of uniaxial tensile stress and the results are tabulated in Table 4. It should be noted that $n_{u}$ must be equal to $n_{b}$ in order to have the same $m$-value for all strains. Once the $m$ values are caiculated, the stress-strain behavior for plane-strain compression can be predicted by theory and the merit of any particular yield criterion can be assessed by comparison with experiment. Again, we use the concept of 


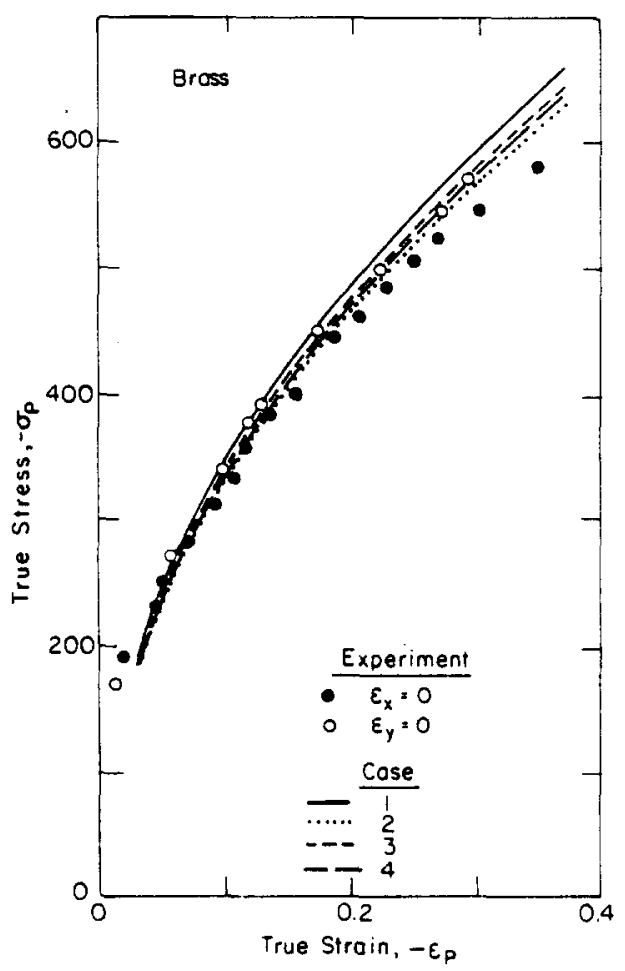

FIG. 4. Plane-strain compression results comparing predictions vs experiment for an alpha brass.

the equivalence of mechanical work for uniaxial tension and plane-strain compression, and assume that the value of $m$ does not vary with strains. Here, the true strain, $\varepsilon_{u}$, in uniaxial tension and the true thickness strain, $\varepsilon_{p}$, in planestrain compression are related by

$$
\sigma_{u} \mathrm{~d} \varepsilon_{u}=\sigma_{p} \mathrm{~d} \varepsilon_{p} \quad \text { or } \quad \varepsilon_{u}=\left(-\frac{\sigma_{p}}{\sigma_{u}}\right)\left(-\varepsilon_{p}\right) .
$$

The uniaxial tensile behavior is again given by $\sigma_{u}=K_{u} \varepsilon_{u}^{n}$ and with equation (35), the predicted stress strain behavior for plane-strain compression is expressed as

$$
-\sigma_{p}=\sigma_{u}\left(-\frac{\sigma_{p}}{\sigma_{u}}\right)=K_{u}\left(-\frac{\sigma_{p}}{\sigma_{u}}\right)^{n+1}\left(-\varepsilon_{p}\right)^{n}=K_{p}\left(-\varepsilon_{p}\right)^{n},
$$

where both $\sigma_{p}$ and $\varepsilon_{p}$, are compressive as to sign. Since the $m$-values for all cases vary with strain, as seen in Table 4 , we have arbitrarily chosen the $m$-value associated with a uniaxial tensile strain of 0.100 to obtain the predicted values summarized in Table 5. To illustrate the procedure, we will analyze the Al-killed steel for Case 1. Here, $r=1.802$ (Table 1), $m=1.999$ (Table 4), and $f / c=-2.5549$ as found earlier.

Using equation (19), $x$ is found first. There are two values of $x$ that satisfy this equation, but since $x$ must be less than 1.0 to satisfy the physics of this situation, the value of 0.357 is chosen. With equation (18) the value of $\left(-\sigma_{p} / \sigma_{u}\right)$ is 1.305. With $K_{u}=524.9$ and $n_{u}=0.234$ (both from Table 1), the use of equation (36) gives $K_{p}=728.9$. Using the values from Table 5 , the predicted plane-strain compression behavior for all four cases is compared with experimental data in Figs 1 to 4.

\section{DISCUSSION}

As seen in Figures 1 to 4, the predicted plane-strain compression stress-strain behavior is fairly similar for all four special cases of Hill's new criterion where Case 1 consistently gives the highest level, Case 2 the lowest, while Cases 3 and 4 are not only between the extremes, but themselves are almost identical. Except for the Al-killed steel. stress-strain behavior that is predicted for the other three metals is generally a bit higher than the experimental findings. It is certainiy possible that the discrepancies can be attributed to at least two sources. First, as seen in Table 4 , the $m$-value varies with strain and all predictions were based upon that value associated with an arbitrarily chosen strain of 0.100 .* $^{*}$

Secondly, the metals themselves do not exhibit planar isotropy so the use of an average $r$-value remains questionable. Even though this approach is technically incorrect, as pointed out in [1], it has been used in most past studies of the type presented here. Although we have no better suggestion at this time, this remains a questionable point.

Finally, we note that the calculated stress ratios $(x)$ for all cases under plane-strain compression are less than 0.5 . whereas, if $m=2$, they should equal $1 /(1+r)$.

* We note that Wagoner [7] and Mohammed-Ali and Mellor [8] have observed similar behavior. 


\section{CONCLUSIONS}

Although discrepancies exist between prediction and experiment, all four cases give reasonable results from a practical point of view. Cases 1 and 4 are somewhat simpler in formulation than are Cases 2 and 3 and from Figs 1 to 4, there is a slight preference for Case 4.

Acknowledgements-Dr C. Vial obtained the results shown in Tables 1 to 3 during his Ph.D. program at The University of Michigan, under NSF grant DMR-7923231. Dr C. H. Toh and Mr Y. T. Im, at the University of California at Berkeley, helped in the computations for Tables 4 and 5 .

\section{REFERENCES}

1. C. VIAL, W. F. HoSFORd and R. M. CADDELL, Int. J. Mech. Sci. 25, 899 (1983).

2. R. Hill, Math. Proc. Cambridge Phil. Soc. 85, 179 (1979).

3. B. DODd and R. M. CADdell, Int. J. Mech. Sci. 26, 113 (1984).

4. J. Woodthorpe and R. PearCe, Int. J. Mech. Sci. 12, 341 (1970).

5. A. PArmar and P. B. Mellor, Int. J. Mech. Sci. 20, 385 (1978).

6. A. PARMar and P. B. Mellor, Int. J. Mech. Sci. 20, 707 (1978).

7. R. H. WAGONER, Met. Trans. A. 11A, 165, (1980).

8. Personal Communication from P. B. MelLoR to R. M. CADDELL, entitled, Constitutive relations and forming limit criteria, by A. Mohammed-Ali and P. B. Mellor (1984). 